\title{
The effect of non-stunned and stunned halal slaughter method on broiler breast meat quality
}

\begin{abstract}
Purpose: This study was designed to investigate the effect of pre-slaughter treatment, i.e. stunned vs. non-stunned, on the quality attributes of Halal broiler breast meat.

Design/methodology/approach: Samples of non-stunned broiler breast meat $(n=10)$ and stunned broiler breast meat $(\mathrm{n}=10)$ which have undergone the Halal slaughter method were analysed on the quality parameters of protein solubility, emulsion activity index, emulsion stability index, $\mathrm{pH}$, water holding capacity (drip loss and cooking loss), texture (shear force textural analysis), meat colour ( $\mathrm{L}, \mathrm{a}, \mathrm{b}$ analysis) and sensory evaluation. The results were then analysed for statistical differences using the Mann-Whitney Test on SPSS.
\end{abstract}

Findings: The study revealed that stunned meat had a significantly higher protein solubility compared to non-stunned meat $(\mathrm{p}<0.05)$. However, no significant differences were found between the two samples for emulsion activity index, emulsion stability index, $\mathrm{pH}$ and water holding capacity. Texture analysis revealed that cooked samples of stunned meat was significantly tougher than cooked samples of non-stunned meat $(\mathrm{p}<0.05)$. This correlated with sensory analysis where the non-stunned meat was preferred on overall. Non-stunned meat samples exhibited significantly lower lightness $\left(\mathrm{L}^{*}\right)$ and yellowness values $\left(\mathrm{b}^{*}\right)$ and significantly higher redness $\left(\mathrm{a}^{*}\right)$ and Chroma $\left(\mathrm{C}^{*}\right)$ values as compared to stunned meat $(\mathrm{p}<0.05)$.

Research limitations/implications: Further analysis on glycogen content, lactic acid content and measurements of proteolytic activity (cathepsins and calpains) could be undertaken to further support the study. A trained panel using a scoring method with a bigger sample group could be undertaken for more detailed sensory analysis.

Originality/value: There are studies comparing different stunning methods on broiler meat quality but no present study comparing non-stunning and stunning on Halal broiler meat quality.

Keywords: halal slaughter, stunning, non-stunning, poultry meat, broiler meat, meat quality
Volume I Issue 3 - 2015

\author{
Wong MM,Ashton I \\ Centre of Nutrition, Dietetics and Food Science, Cardiff \\ Metropolitan University, UK
}

Correspondence: Wong MM, Centre of Nutrition, Dietetics and Food Science, Cardiff Metropolitan University, Cardiff, UK, Email michelle.wmiyi@gmail.com

Received: July 2, 2015 | Published: September 21, 2015

\section{Introduction}

According to legislation under The Welfare of Animals (Slaughter or Killing) Regulations 1995, all animals that are to be slaughtered are required to undergo pre-stunning. However, under Schedule 12 of the mentioned regulation, there are exemptions for religious slaughter for both the Jewish and Muslim communities, i.e., the Shechita and Halal method of slaughter respectively. Out of the two (Halal and Shechita), the demand for Halal slaughtered meat worldwide is far greater due to the growing Muslim population which is forecasted to represent $27 \%$ of the global population by $2030 .{ }^{1}$ Halal is an Arabic term meaning 'allowed' or 'lawful. '. In the halal slaughtering process, animals have to be restraint and the name of Allah must be declared during the act of slaughter while severing the neck of the animal with a sharp blade to achieve instant and copious exsanguinations. ${ }^{3}$ On the other hand, halal slaughter described by the Department of Islamic Development Malaysia ${ }^{4}$ allows pre-stunning of the animal before the severing of the trachea, oesophagus and both the carotid and jugular veins. Many Muslim authorities and Halal accreditation bodies such as the GCC Member States, Indonesia, Malaysia and the Islamic Food and Nutrition Council of America are slowly accepting the use of stunning in Halal slaughter with certain strict exceptions. According to the latest version of the OIC Halal Standards ${ }^{3}$ and the Malaysian Standards MS, ${ }^{5}$ stunning of the animal in Halal slaughter is permitted if the stunning is reversible, i.e. the animal must still be alive and not undergo any permanent injury during the use of the stunning. However, this can be tricky as dead animals can develop false aneurysms which could be mistaken for the animal still being alive. ${ }^{6}$ $\mathrm{EFSA}^{7}$ explained that pre-stunning an animal serves the purpose of rendering the animal insensible. According to the EFSA, if not stunned, the animal only becomes unconscious after a certain degree of blood loss and this can be up to 20seconds in sheep and 2 minutes in cattle. Therefore, if not stunned, the animals will experience fear, pain, panic and other adverse effects such as the inhalation of blood because of bleeding into the trachea which can potentially affect the meat quality. While there is debate on whether the stunning or nonstunning is more religiously acceptable in the Halal slaughter method, both parties agree that animals should be slaughtered in the most humane conditions to protect animal welfare.

On the contrary of the animal welfare concerns of non-stunning as claimed by the EFSA, Anil ${ }^{3}$ stated that if stunning is not done properly, this too can also negatively affect the carcass and meat quality causing 
conditions such as PSE (pale, soft and exudative) or DFD (dark, firm and dry) as well as meat toughness manifested in the eating quality. If animals are mishandled pre-slaughter, blood splashes and hemorrhages can also be observed. While there are existing studies comparing the effects of non-stunning and stunning on the animal, these studies only cover red meat and game meat. Studies conducted by Nakyinsige et al., ${ }^{8}$ Verlade et al. ${ }^{9}$ \& Vergara et al. ${ }^{10}$ on rabbit meat and lamb meat respectively showed that there were considerable differences in meat quality between non-stunned and stunned meat. In addition, studies conducted by Linares et al., ${ }^{11}$ Onen $\mathrm{C}$ et al. ${ }^{12}$ \& Goksoy et al., ${ }^{13}$ on lamb, cattle and broiler meat respectively also showed differences in meat quality between the uses of different stunning methods. However, there are not sufficient studies undertaken on whether there are any adverse intrinsic and functional effects on broiler carcass and meat quality between non-stunning and stunning of the animal. In addition to that, existing studies available on white meat only compare samples between the uses of different stunning methods. At the same time, the quality measures were limited to $\mathrm{pH}$, colour, $\mathrm{WHC}$ and shear force. Therefore, more additional parameters could be tested and compared. As a result, the present study was designed to investigate the effect of non-stunned and stunned Halal slaughter method on broiler breast meat quality and covers extended meat quality parameters such as protein solubility as well as emulsion activity index and emulsion stability index.

\section{Materials and method}

\section{Sample selection}

A total of 30 skinless, boneless breast fillets were initially selected from a local processing plant (Gafoor Poultry, Preston, UK). The broiler breast samples were divided into two sample groups: 15 pieces of non-stunned halal slaughtered chicken breasts and 15pieces of stunned halal slaughtered chicken breasts. Chickens (Gallus gallus domesticus) from both groups received the same diet, were of the same broiler variety (Ross Cobb 308), kill age (37days before slaughter), average weight and raised and shackled before Slaughter in the same environment. In the non-stunned halal slaughter method, the chickens were humanely slaughtered at the processing plant by severing the carotid artery, jugular vein, trachea and oesophagus. In order to carry out the stunned slaughter method, the chickens were put in an electrical water bath for 5 seconds at $0.25 \mathrm{~A}$. All the chickens were subsequently bled out to drain all excess blood from the carcass. The breast samples were then obtained from both groups and placed in plastic bags, chilled to $\leq 5^{\circ} \mathrm{C}$ and transported to Cardiff Metropolitan University at the same temperature. Five whole chicken breast samples from each group were kept aside and labeled to be used for sensory analysis. The remaining ten samples were portioned in half, individually packed and labeled accordingly, to be used for objective quality analysis. Half portions of each sample were individually minced in a Kitchen Aid food processor (Magimix R1 1800) for 1 minute. All analyses were carried out on chilled meat samples that were stored at $\leq 5^{\circ} \mathrm{C}$ over 12 days.

\section{pH measurement}

Approximately $2 \mathrm{~g}$ of minced chicken breast was homogenized with $18 \mathrm{~mL}$ of distilled water. The $\mathrm{pH}$ of the homogenate was determined using a pH meter (Fisher brand Hydrus 300) upon receiving the samples (initial $\mathrm{pH}$ ), day 4 and day 5 of storage.

\section{Protein solubility measurements}

Procedures described in Farouk et al. ${ }^{14}$ were modified and used to determine protein solubility. To determine total soluble protein, $1 \mathrm{~g}$ of minced meat was weighed into a centrifuge tube, $20 \mathrm{ml}$ of $1.1 \mathrm{M}$ potassium iodide in $0.1 \mathrm{M}$ phosphate buffer $(\mathrm{pH} 7.4)$ added and the meat and buffer homogenized manually using a potter homogenizer. The contents were centrifuged (3500 RCF, 15min) using a Sony Harrier $15 / 80 \mathrm{MSE}$ and the protein content in the supernatant determined by the Bradford method. ${ }^{15}$ To determine soluble sarcoplasmic protein, a second sample of mince was subjected to the same method of extraction, using $0.03 \mathrm{M}$ phosphate buffer ( $\mathrm{pH} 7.4)$. The soluble myofibrillar protein was calculated as the difference between total soluble protein and sarcoplasmic protein. Tests were done for ten samples each of stunned chicken and non-stunned chicken and the means expressed as percentage $(\mathrm{g} / 100 \mathrm{~g})$ of meat.

\section{Water holding capacity: drip loss}

Meat samples were cut from each chicken breast and immediately weighed. Each sample was wrapped in absorbing paper, placed in a clear plastic bag and stored in chilled temperatures (1to5degrees). The samples were then weighed after 1day, 4days and 5days after storage, in every case the initial weight is used as the reference point. The drip loss was expressed as a percentage of the initial weight.

\section{Water holding capacity: cooking loss}

Meat samples were cut from each chicken breast and immediately weighed. The samples were then poached in boiling water and cooked until the samples have reached a defined internal temperature of $75^{\circ} \mathrm{C} .{ }^{16}$ Once this temperature has been reached, the samples were removed from the boiling water, blotted dry and then weighed. The cooking loss was expressed as a percentage of the initial sample weight.

\section{Emulsion activity index and emulsion stability index}

Referring to the method described by Chan et al., ${ }^{17}$ sarcoplasmic protein solution was prepared by homogenising $1 \mathrm{~g}$ of meat with $20 \mathrm{ml}$ of $0.03 \mathrm{M}$ phosphate buffer ( $\mathrm{pH} 7.4$ ), Homogenates were centrifuged using a Sony Harrier $15 / 80 \mathrm{MSE}$ at $3500 \mathrm{RCF}$ for 15 minutes and filtered through Whatman no. 1 filter paper (Whatman, Kent, UK). The supernatant obtained after filtration was used as sarcoplasmic protein solution. Myofibrillar protein solution was prepared after separation of sarcoplasmic proteins. The sediment was further homogenized with $20 \mathrm{ml}$ of $0.05 \mathrm{M}$ phosphate buffer containing $0.55 \mathrm{M} \mathrm{KI}(\mathrm{pH} 7.4)$. Homogenates were centrifuged at $3500 \mathrm{RCF}$ for 15 minutes and filtered through Whatman no.1 filter paper. The supernatant obtained after filtration was used as myofibrillar protein solution. The protein concentration of the supernatants was assessed using the Bradford method. ${ }^{15}$ The emulsion activity index (EAI) was determined according to the modified method described by Chan et al. ${ }^{17}$ Known volumes of protein at two different concentrations $(1.5 \mathrm{mg} /$ $\mathrm{ml}$ and $3 \mathrm{mg} / \mathrm{ml}$ ) were prepared and mixed with sunflower oil in the ratio of $3: 1$ by homogenisation. Immediately after homogenisation, aliquots of $25 \mathrm{uL}$ of the emulsion were diluted to $2.5 \mathrm{~mL}$ with $0.1 \%$ SDS solution. The turbidity of the emulsion was measure at $500 \mathrm{~nm}$ using a spectrophotometer (WPA S800 Spectra wave). The EAI was measured as initial absorbance and was calculated from the equation as below:

$$
E A I=2.33 \times A_{0}
$$


where $\mathrm{A}_{0}$ is the absorbance measured immediately after emulsion preparation.

The emulsion stability index (ESI) was determined by measuring the absorbance of the emulsion after 10minutes. The ESI was calculated from the equation:

$$
E S I=10 \times\left[\frac{A_{0}}{\left(A_{0}-A_{10}\right)}\right]
$$

where $\mathrm{A}_{10}$ is the absorbance measured after 10 minutes.

\section{Meat colour}

High resolution photographs (captured in RAW format and converted to DNG) were taken of each whole chicken breast (front and back) on the day of receiving the samples under neutral lighting using a Canon SX50. L* (lightness), a* (red colour coordinate) and $b^{*}$ (yellow colour coordinate) were measured using the Lab colour profile function in Adobe Photoshop

CS5. $C^{*}$ (Chroma) defined as the square root of $(a * 2+b * 2)$ was also calculated.

\section{Meat textural analysis (Shear force)}

Meat texture of raw and cooked meat were assessed using the Warner Bratzler shear test (TA.XT plus Texture Analyzer). Sample strips were cut with an approximately $100 \mathrm{~mm}^{2}(10 \mathrm{x} 10)$ cross section with the fibre direction parallel direction parallel to a long dimension of at least $30 \mathrm{~mm}$.

\section{Sensory evaluation}

Sensory evaluation was conducted in a sensory kitchen following the standard sensory practices (Cardiff Metropolitan University, Cardiff, UK). A select panel of 8 panellists, consisting of staff from the university's Food Industry Centre (FIC) and final year Food Science and Technology students were recruited to compare stunned and nonstunned Halal chicken breast in the poached state. The evaluation session was conducted as an open discussion and judgments' for each attribute were recorded as verbal descriptors. For cooked samples, the colour, odour, tenderness, juiciness and overall acceptability were evaluated. Whole breast muscles were put into boiling water for approximately 15 to 20 minutes to an internal temperature of $75^{\circ} \mathrm{C}^{16}$ a calibrated temperature probe (HygiPlas Catertherm) was used to monitor end point temperature. Cooked samples were cut into equal sized cubes and coded numerically. The samples were served to each of the panellists immediately after preparation. Raw chicken samples were also assessed on colour and odour. The evaluation recorded from the panellists unanimously is analysed qualitatively.

\section{Statistical analysis}

SPSS (version 20) was used for data analysis. The Mann-Whitney test was used to test for differences between samples $(n=20)$. In all cases, $\mathrm{P} \leq 0.05$ was taken as statistically significant.

\section{Results}

\section{pH measurement}

The initial $\mathrm{pH}$ for both samples was an average of 6.3 for the nonstunned chicken breast and 6.34 for the stunned chicken breast (Table
1). On day 4 , the average $\mathrm{pH}$ of the non-stunned samples was 6.46 with an average $\mathrm{pH}$ rise of 0.16 while the stunned chicken samples had an average $\mathrm{pH}$ of 6.42 with an average $\mathrm{pH}$ rise of 0.08 . The $\mathrm{pH}$ of both samples continued to rise on day 5 resulting in an average of $\mathrm{pH} 6.885$ for the non stunned chicken samples and $\mathrm{pH} 6.901$ for the stunned chicken samples. The $\mathrm{pH}$ change between the two, however, were not significant $(\mathrm{p}>0.05)$.

Table I Means $( \pm S . D$. $)$ of $\mathrm{pH}$ levels between non-stunned and stunned chicken breast

\begin{tabular}{llll}
\hline Trait & NS & S & P-value \\
\hline $\mathrm{pH}^{\text {inital }}$ & $6.30 \pm 0.14$ & $6.34 \pm 0.08$ & - \\
$\mathrm{pH}^{\text {day4 }}$ & $6.46 \pm 0.21$ & $6.42 \pm 0.14$ & 0.353 \\
$\mathrm{pH}^{\text {day } 5}$ & $6.89 \pm 0.13$ & $6.90 \pm 0.10$ & 0.579 \\
\hline
\end{tabular}

\section{Protein solubility}

Protein solubility differed significantly across the two groups of samples $(\mathrm{p}<0.001)$ (Table 2$)$. The mean values of total soluble protein (TSP), sarcoplasmic soluble protein (SSP) and myofibrillar soluble protein (MSP) for the non-stunned chicken breast samples were 46.7, 30.8 and $15.9 \mathrm{~g} / 100 \mathrm{~g}$ respectively. On the other hand, the mean values of TSP, SSP and MSP for stunned chicken breast samples are 96.7, 48.4 and $48.3 \mathrm{~g} / 100 \mathrm{~g}$ respectively.

Table 2 Means ( \pm S.D.) of protein solubility in non-stunned and stunned chicken breast samples

\begin{tabular}{llll}
\hline Trait & NS & S & P-value \\
\hline Total Soluble Protein & $46.7 \pm 11.5$ & $96.7 \pm 7.4$ & 0.001 \\
Sarcoplasmic Soluble Protein & $30.8 \pm 5.4$ & $48.4 \pm 6.9$ & 0.001 \\
Myofibrillar Soluble Protein & $15.9 \pm 14.7$ & $48.3 \pm 15.1$ & 0.001 \\
\hline
\end{tabular}

\section{Drip loss}

On day 1, drip loss was higher in non-stunned chicken breast with an average percentage loss of $6.9 \%$ while the average percentage of drip loss in stunned chicken breast was $5.0 \%$ (Table 3). Drip loss of stunned chicken breast was higher on day 4 with an average percentage drip loss of $11.8 \%$ while non-stunned chicken breast had an average drip loss percentage of $11.4 \%$. However, the drip loss between the two samples were not significant $(\mathrm{p}>0.05)$.

Table 3 Means ( \pm S.D.) of water holding capacity (drip loss and cooking loss) for non-stunned and stunned chicken breast

\begin{tabular}{lllll}
\hline Traits & & NS & S & P-value \\
\hline & Day 1 & $6.9 \pm 6.1$ & $5.0 \pm 1.1$ & - \\
Drip Loss (\%) & Day 4 & $11.4 \pm 4.7$ & $11.8 \pm 3.0$ & 0.353 \\
& Day 5 & $15.5 \pm 5.3$ & $15.4 \pm 3.3$ & 0.739 \\
Cooking Loss (\%) & & $36.0 \pm 8.0$ & $38.3 \pm 10.3$ & 0.853 \\
\hline
\end{tabular}

\section{Cooking loss}

Cooking loss was less in non-stunned chicken breast (36.0\%) compared with stunned chicken breast (38.3\%) (Table 3). However, the cooking losses were not significantly different between the two samples. 


\section{Emulsion activity index and emulsion stability index}

The mean Emulsion Activity Index (EAI) for sarcoplasmic protein at $1.5 \mathrm{mg} / \mathrm{ml}$ was observed to be higher in the non-stunned chicken sample as compared to the stunned chicken sample with means of 0.096 and 0.075 respectively (Table 4). At $3.0 \mathrm{mg} / \mathrm{ml}$, the mean EAI for sarcoplasmic protein was lower in the non-stunned samples. However, the differences between the samples were not found to be significant $(\mathrm{p}>0.05)$.

The mean EAI for myofibrillar protein at both $1.5 \mathrm{mg} / \mathrm{ml}$ and $3.0 \mathrm{mg} /$ $\mathrm{ml}$ were higher in the non-stunned chicken breast samples with means of 0.092 for both concentrations as compared to the stunned chicken breast samples with an EAI mean of 0.059 at $1.5 \mathrm{mg} / \mathrm{ml}$ and 0.064 at $3.0 \mathrm{mg} / \mathrm{ml}$ (Table 4). The differences between the two samples were Table 4 Means $( \pm$ S.D.) of emulsion activity index and emulsion stability index of sarcoplasmic and myofibrillar proteins in non-stunned and stunned chicken breast samples

\begin{tabular}{|c|c|c|c|c|c|c|c|c|}
\hline & \multicolumn{4}{|c|}{ Emulsion activity index } & \multicolumn{4}{|c|}{ Emulsion stability index } \\
\hline & \multicolumn{2}{|c|}{$\begin{array}{l}\text { Sarcoplasmic protein }(\mathrm{mg} / \\
\mathrm{ml})\end{array}$} & \multicolumn{2}{|c|}{$\begin{array}{l}\text { Myofibrillar protein(mg/ } \\
\text { ml) }\end{array}$} & \multicolumn{2}{|c|}{$\begin{array}{l}\text { Sarcoplasmic protein }(\mathrm{mg} / \\
\mathrm{ml})\end{array}$} & \multicolumn{2}{|c|}{$\begin{array}{l}\text { Myofibrillar protein(mg/ } \\
\text { ml) }\end{array}$} \\
\hline & 1.5 & 3 & 1.5 & 3 & 1.5 & 3 & 1.5 & 3 \\
\hline NS & $0.096 \pm 0.052$ & $0.094 \pm 0.033$ & $0.092 \pm 0.056$ & $0.092 \pm 0.056$ & $16.2 \pm 25.6$ & $22.9 \pm 26.3$ & $15.6 \pm 13.9$ & $3.9 \pm 5.6$ \\
\hline S & $0.075 \pm 0.046$ & $0.116 \pm 0.078$ & $0.059 \pm 0.048$ & $0.064 \pm 0.045$ & $60.7 \pm 118.2$ & $9.6 \pm 16.7$ & $16.7 \pm 8.5$ & $8.3 \pm 7.5$ \\
\hline P-value & 0.353 & 0.796 & 0.075 & 0.247 & 0.436 & 0.19 & 1 & 0.247 \\
\hline
\end{tabular}

\section{Meat colour}

The $\mathrm{L}^{*}$ coordinates for the stunned chicken samples were higher than the non-stunned samples with means of 59.20 and 53.57 respectively (Table 5). However, the a* coordinates were higher for the non-stunned samples as compared to the stunned samples with means of 12.83 and 6.10 respectively. The stunned samples had a higher $b^{*}$ coordinate mean of 7.03 as compared to the non-stunned samples of 3.77. The $\mathrm{C}^{*}$ coordinates of the non-stunned samples was higher than the stunned samples with means of 13.45 and 9.45 respectively. All values were found to be significantly different between both samples $(\mathrm{p}<0.001)$.

Table 5 Means ( \pm S.D.) of colour coordinate values between non-stunned and stunned chicken samples

\begin{tabular}{llll}
\hline Colour coordinates & NS & S & P-value \\
\hline$L^{*}$ & $53.57 \pm 3.46$ & $59.20 \pm 2.63$ & 0.001 \\
$a^{*}$ & $12.83 \pm 2.69$ & $6.10 \pm 0.94$ & 0.001 \\
$b^{*}$ & $3.77 \pm 1.18$ & $7.03 \pm 1.82$ & 0.001 \\
$C^{*}$ & $13.45 \pm 2.50$ & $9.45 \pm 1.11$ & 0.001 \\
\hline
\end{tabular}

\section{Meat textural analysis}

The peak force of the cooked stunned samples was higher than the cooked non-stunned samples with peak force means of $2929.0 \mathrm{~g}$ and 2403.0g respectively (Figure 1). The difference between the two samples were found to be significant $(p<0.003)$. The peak force of the raw stunned samples was higher than the raw non-stunned samples with peak force means of $1853.8 \mathrm{~g}$ and $1584.7 \mathrm{~g}$ respectively (Figure reportedly found to be not significant ( $\mathrm{p}>0.05$ ). The mean Emulsion Stability Index (ESI) (Table 4) below for sarcoplasmic protein at $1.5 \mathrm{mg} / \mathrm{ml}$ was observed to be higher in stunned chicken sample as compared to the non-stunned chicken sample with means of 60.7 and 16.2 respectively. At $3.0 \mathrm{mg} / \mathrm{ml}$, the mean of ESI for sarcoplasmic protein was lower in the stunned samples. However, the differences between the samples were not found to be significant $(\mathrm{p}>0.05)$. The mean ESI for myofibrillar protein at both $1.5 \mathrm{mg} / \mathrm{ml}$ and $3.0 \mathrm{mg} / \mathrm{ml}$ were lower in the non-stunned chicken breast samples with means of 15.6 and 3.9 respectively (Table 4). The stunned chicken breast samples had a higher ESI mean of 16.7 at $1.5 \mathrm{mg} / \mathrm{ml}$ and 8.3 at $3.0 \mathrm{mg} /$ $\mathrm{ml}$. However, the differences between the samples were not reportedly significant $(\mathrm{p}>0.05)$.
2). However, the difference between the two samples were not significant $(\mathrm{p}>0.05)$.

\section{Sensory evaluation}

In the raw chicken samples, more blood spots were observed in the non-stunned chicken breasts as compared to the stunned. A darker colour due to multiple bruising was also observed on the raw non-stunned chicken samples, whilst the stunned samples were paler in colour (Figures 3.1) (Figure 3.2) \& (Figure 4.1) (Figure 4.2). On the cooked samples, the stunned chicken breast reportedly had a stronger and more metallic odour than the non-stunned chicken breast. Tenderness, flavor and juiciness were more preferable with the non-stunned chicken breast as it had a sweeter flavor, more moist and was softer than the stunned chicken breast. Although both were of acceptable eating quality, the non-stunned chicken breast was unanimously preferred on overall acceptability. These results correlate with the objective quantitative texture analysis data (Figure 1).

\section{Discussion \\ pH measurement}

Both sample groups exhibited high ultimate $\mathrm{pH}$ (Table 1). Though there were not any described statistical differences, the higher $\mathrm{pH}$ value in the stunned samples agree with Linares et al. ${ }^{11}$ and Nakyinsige et al., ${ }^{8}$ findings for lamb and rabbit samples respectively. Papinaho et al., ${ }^{18}$ also found that non-stunned meat had lower $\mathrm{pH}$ values as compared to stunned meat. The ultimate $\mathrm{pH}$ of the muscle tissue is dependent on the degradation of glycogen to lactic acid, i.e. post mortem glycolysis. The dynamics of lactic acid formation is closely related to the state of the chicken before slaughter, i.e. whether 
the birds are tired or stressed pre-slaughter. ${ }^{19}$ The high $\mathrm{pH}$ values in both sample groups indicated that the animals suffered from chronic stress and used up all their glycogen before slaughter which resulted in glycogen deficiency in the muscles of the birds. ${ }^{20}$ This prevented sufficient lactic acid formation for muscle $\mathrm{pH}$ values to reach lower than 6.0 after slaughter in both sample groups. It is also possible that the higher value of $\mathrm{pH}$ observed in stunned group (Table 1) could be due to a high level of catecholamine's which is related to preslaughter fear. ${ }^{21}$ On the other hand, Lengerken et al., ${ }^{22}$ claims that meat with a high ultimate $\mathrm{pH}$ value usually results in the development of DFD (dark, firm and dry) meat. This also agrees with Mallia et al.'s research ${ }^{23}$ which suggests that poultry meat $\mathrm{pH} 6.3$ and higher can be classified as DFD. However, although both sample groups fall under the DFD classification based on their high $\mathrm{pH}$ values, it is not sufficient to qualify the chicken breast meat samples as DFD defective.

\section{Protein solubility}

The stunned sample group had significantly higher protein solubility than the non-stunned group (Table 2). $\mathrm{pH}$ and temperature are two factors that can affect protein solubility in meat. According to Joo et al. $^{24}$ and Warner et al., ${ }^{25}$ muscles with a lower $\mathrm{pH}$ and higher temperature are more susceptible to a higher extent of protein denaturation than muscles with a higher $\mathrm{pH}$ and lower temperature. As the non-stunned sample group had a lower $\mathrm{pH}$, it is possible that it had undergone greater protein denaturation than the stunned sample group (Table 2). In order to confirm this correlation, temperatures of the muscles could be measured in future studies. Although there have not been any comparative studies carried out on between the two groups, Joo et al., ${ }^{24}$ investigated the protein solubility between the different quality classes of pork, namely PSE (pale, soft, exudative), RSE (reddish-pink, soft, exudative), RFN (reddish-pink, firm, nonexudative) and DFD (dark, firm, dry). It was found that the PSE samples exhibited significantly lower protein solubility (sarcoplasmic, myofibrillar and total) compared to the other quality classes. The study also showed that the RSE samples exhibited significantly lower sarcoplasmic protein solubility compared to DFD samples and that RSE, RFN and DFD samples has similar myofibrillar and total protein solubilities. Warner et al., ${ }^{25}$ also found protein solubility in pork to be lower in PSE samples while RSE samples had similar protein solubility to RFN. The study also found that RSE had lower values than DFD samples for protein solubility.

\section{Water holding capacity (drip loss and cooking loss)}

Both sample groups did not exhibit differences in drip loss (Table 3). Similar research supports this study's findings Nakyinsige et al. ${ }^{8} \&$ Vergara et al. ${ }^{26}$ studies on rabbits and lambs respectively showed that the drip loss between the stunned and non-stunned samples did not differ. Furthermore, Verlade et al., ${ }^{9}$ study did not show any difference between chilling loss of stunned and non-stunned lambs.

Much of the water inside living muscle cells is located within the myofibril. Myofibrillar proteins in meat are said to have an isoelectric point of approximately $\mathrm{pH}$ 5.4. As myofibrillar proteins reach further away from their isoelectric points, the ability to bind water changes. ${ }^{27}$ Therefore, the similar drip loss values in both sample groups correspond to both sample groups having similar $\mathrm{pH}$ values. Although not statistically significant, the stunned sample group exhibited a higher cooking loss (Table 3).
Nakyinsige et al. ${ }^{8}$ \& Linares et al., ${ }^{11}$ research agrees with this study's findings that non-stunned animals exhibit a lower cooking loss compared to stunned animals. However, Onen $\mathrm{C}$ et al., ${ }^{12}$ research found that stunned meat had lower cooking losses as compared to non-stunned meat which disagrees with this study. Heating muscle tissue causes denaturation and coagulation of the myofibrillar proteins which in turn causes the shrinkage of myofilaments and a tightening of the microstructure of myofibrils which also decreases the muscle's water holding capacity as it increases the amount of free water in the muscle. ${ }^{28,29}$ Since there was a higher amount of soluble myofibrillar proteins in the stunned samples, there was also more protein denaturation caused by heat from cooking which resulted in the stunned samples exhibiting a higher cook loss as compared to the non-stunned samples (Table 3).

\section{Emulsion activity index and emulsion stability index}

There were no statistical differences observed between the two samples groups for EAI and ESI (Table 4). The EAI measures the ability of proteins to rapidly adsorb at the water-oil interface during the formation of an emulsion to prevent flocculation and coalescence while the ESI measures the rate of decrease of emulsion turbidity resulting from droplet coalescence and creaming, which leads to emulsion destabilization. ${ }^{17}$ Both EAI and ESI increase when proteins favour emulsion formation and stabilization respectively. ${ }^{30}$ However, in this study, even though the stunned sample group exhibited significantly higher protein solubility, it was not reflected in the results for EAI and ESI. A possible reason for this could be due to the fact that broiler breast meat is very lean and does that have sufficient fat particles in its composition to entrap any soluble proteins in the samples. In future studies, the EAI and ESI could be measured at different storage times. Although there have not been any comparative studies done with EAI and ESI on non-stunned and stunned meat, Chan et al. ${ }^{17}$ conducted a study on the EAI and ESI values of frozen turkey breast meat with different ultimate $\mathrm{pH}$. The findings reported that the EAI of sarcoplasmic proteins at 1.5 and $3.0 \mathrm{mg} / \mathrm{ml}$ were significantly higher in the high $\mathrm{pH}$ meat samples as compared to the low $\mathrm{pH}$ meat samples while there was no significant difference reported with myofibrillar proteins. In the case of ESI, no significant difference was reported for sarcoplasmic proteins at $1.5 \mathrm{mg} / \mathrm{ml}$ and $3.0 \mathrm{mg} / \mathrm{ml}$ protein concentration. No significant difference was observed for the ESI of myofibrillar proteins.

\section{Meat colour}

The stunned sample group exhibited higher $\mathrm{L}^{*}$ and $\mathrm{b}^{*}$ values while the non-stunned sample group exhibited higher $\mathrm{a}^{*}$ and $\mathrm{C}^{*}$ values (Table 5). This agreed with Nakyinsige et al., ${ }^{8}$ who reported that stunned rabbits showed significantly greater $\mathrm{L}^{*}$ and $\mathrm{b}^{*}$ values on day 1 as compared to non-stunned rabbit meat. The overall findings of the research concluded that non-stunned meat was darker than meat from the stunned group. Linares et al. ${ }^{11}$ also reported that nonstunned meat was found to be darker than stunned meat. Research has attributed the high $\mathrm{L}^{*}$ coordinate value as exhibited by the stunned samples (Table 5) to the possible high level of stress hormones ${ }^{7}$ the high $\mathrm{a}^{*}$ values in the non-stunned meat is due to its bruising and blood spots (Figures 1) \& (Figure 2). Hui \& Sherkat ${ }^{31}$ claimed that handling of birds during the ante mortem stage can cause stress in the animals. At the time of slaughter, the stress caused the venous and arterial systems to transmit severe pressure to the capillary system causing blood splashes and haemorrhages, ${ }^{32}$ (Figures 3.1) \& (Figure 3.2). In 
future studies, meat colour can be measured with a spectrocolorimeter using the International Commission on Illumination (CIE) Lab-values to express meat colour data more accurately.

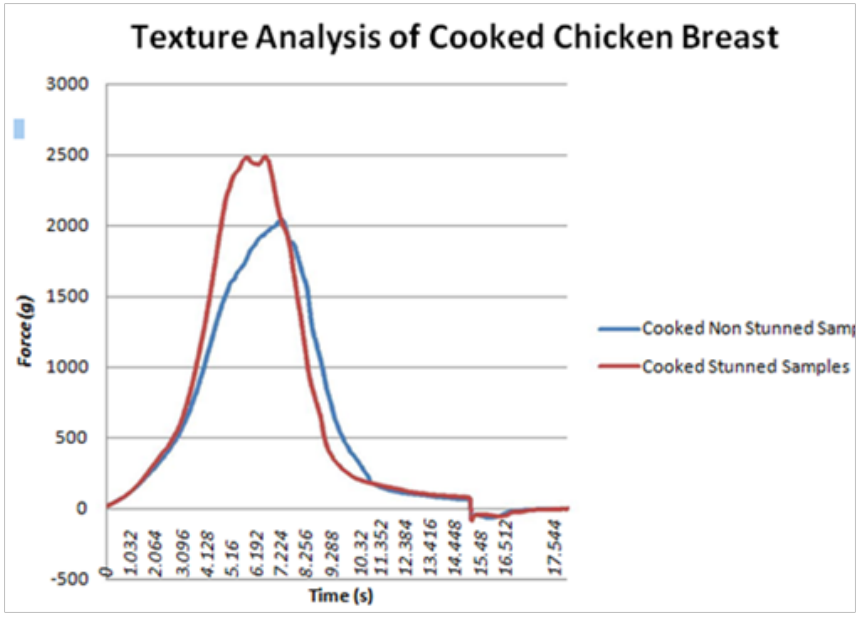

Figure I The mean deformation curves of the warner bratzler shear force (g) against time (s) for cooked samples of stunned and non-stunned chicken breast samples.

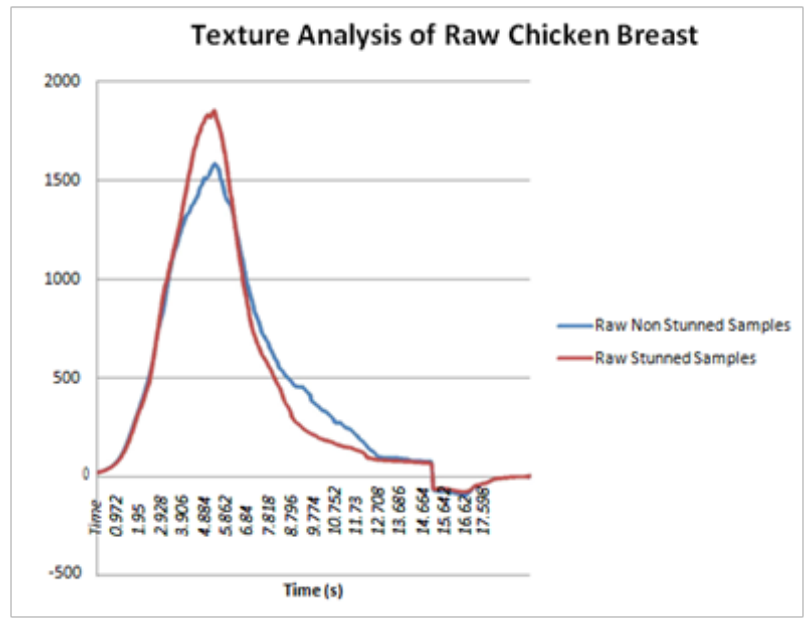

Figure 2 The mean deformation curves of the warner bratzler shear force $(g)$ against time (s) for raw samples of stunned and non-stunned chicken breast samples.

\section{Meat textural analysis (shear force)}

The non-stunned sample group exhibited lower shear force (greater tenderness) than stunned meat (Figures 1) \& (figure 2). Agbeniga et al. ${ }^{33} \&$ Mast et al., ${ }^{34}$ findings agreed with this study. However, Nakyinsige et al. ${ }^{8} \&$ Linares et al. ${ }^{11}$ observed no significant differences between stunned and non-stunned meat. In addition to that, Vergara et al. ${ }^{10}$ \& OnenC et al. ${ }^{12}$ reported that stunned meat was tendered than non-stunned meat. During post mortem proteolysis, the intracellular concentration of $\mathrm{Ca}^{+}$ions increases and stimulate the release of calpains I and II (calcium-activated enzymes) which are responsible for attacking bonds in the contractile proteins. This then loosens the structure of the muscle non-enzymically leading to tenderization. ${ }^{35}$ According to Gregory et al. ${ }^{36}$ stressing an animal for hours before it is killed can make its meat tenderer. Therefore, the higher tenderness observed in the non-stunned samples could be a result of long term pre-slaughter stress which resulted in a higher calpain activity in the said sample group. Further work could be done in future studies to link stress to calpain activity.

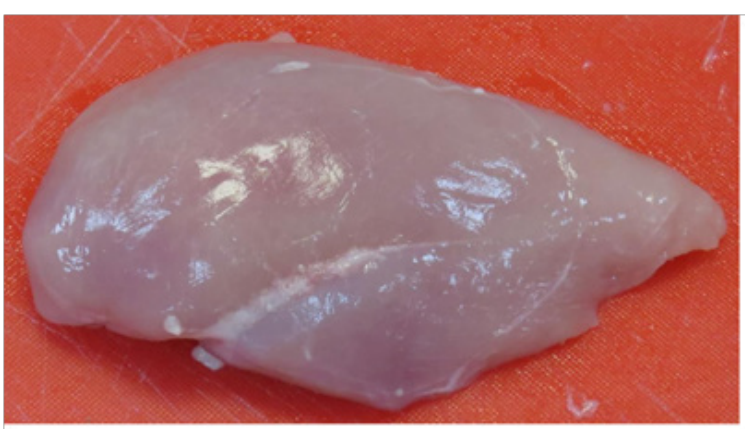

Figure 3.I Halal non-stunned broiler breast (front). The meat appears dark and purplish due to bruising.

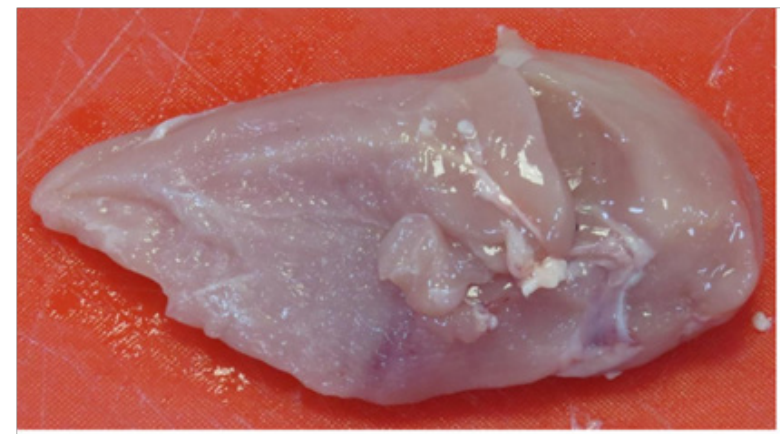

Figure 3.2 Halal non-stunned broiler breast (back). More bruising can be observed. Some blood spots are also evident.

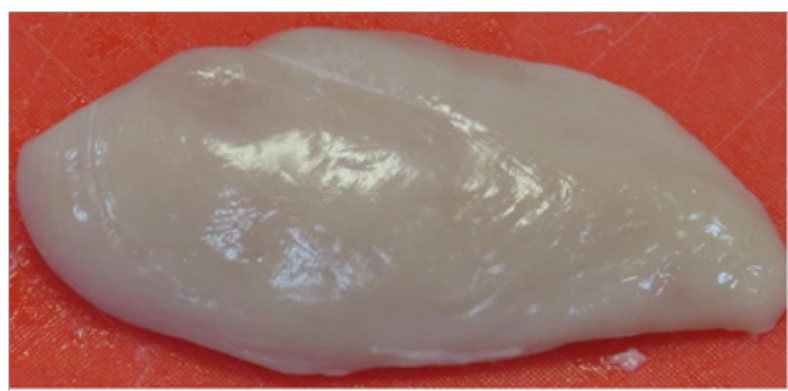

Figure 4.I Halal stunned broiler breast (front). The meat appears paler and no bruising is observed.

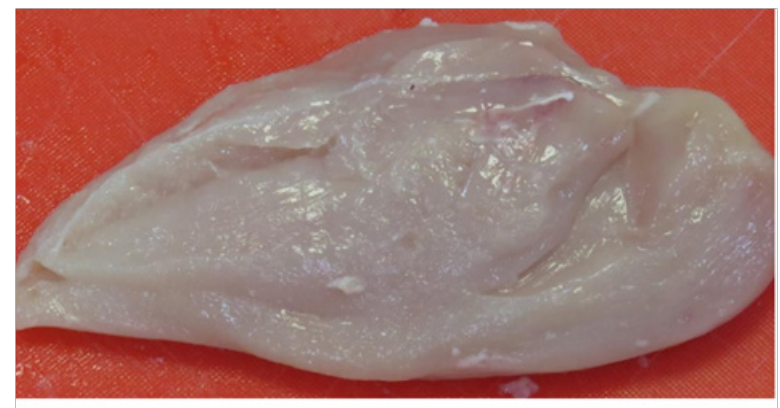

Figure 4.2 Halal non-stunned broiler breast (back). No evident blood spots observed. 


\section{Sensory evaluation}

The non-stunned sample group had a greater overall acceptability (Appendix 1). This disagreed with OnenC and Kaya's ${ }^{11}$ sensory evaluation where steaks derived from stunned animals were more acceptable overall than non-stunned derived steaks. Flavour is the attribute said to be the most affected quality parameter associated with the improper bleeding with the development of a gamey flavour due to the residual blood remaining in the muscles. ${ }^{31}$ Therefore, the metallic odour picked up in the stunned meat could be due to this. Further research to affirm these findings could be done with a trained panel using a scoring method with a bigger sample group.

\section{Conclusion}

This study showed that the non-stunning and stunning methods of Halal slaughter impact a number of quality attributes as indicated by the objective measures obtained. Though both sample groups showed evidence of pre-slaughter stress, e.g., high $\mathrm{pH}$ ultimate; and bruising and blood spots, it is not evident which sample group had undergone the greater stress. The non-stunned sample group exhibited high a* values correlating with less acceptable meat colour as indicated by informal sensory analysis. However, the same sample group of broiler breast meat also exhibited significantly greater tenderness (lower shear force) which resulted in the non-stunned Halal slaughtered meat having a more acceptable textural quality. The study indicates the importance of understanding pre-slaughter processes in delivering acceptable quality attributes to the consumer. Further work needs to be carried out to link stress status with objective quality measurements.

\section{Acknowledgements}

None.

\section{Conflict of interest}

The author declares no conflict of interest.

\section{References}

1. Sunkar I. The global halal trade, trends and issues. The Halal Journal. 2008. p. 32-34.

2. Hussaini MM, Sakr AH. Islamic dietary laws and practices. Chicago IL. USA: The Islamic food and nutrition council of America; 1983.

3. Anil MH. Effects of slaughter method on carcass and meat characteristics in the meat of cattle and sheep. EBLEX and AHDB-A Division of the Agriculture and Horticulture Development Board, UK; 2012. p. 1-73.

4. Department of Islamic Development Malaysia (JAKIM). Malaysian protocol for the halal meat and poultry productions. JAKIM; 2011. $\mathrm{p}$. $1-30$

5. Malaysian Standard MS 1500. Halal Food-Production, preparation, handling and storage-General guideline (first version). Department of Standards Malaysia; 2004. p. 1-13.

6. Nakyinsige K, Che Man YB, Aghwan ZA, et al. Stunning and anima welfare from Islamic and scientific perspectives. Meat Science. 2013;95(2):352-361.

7. EFSA. Welfare aspects of the main systems of stunning and killing the main commercial species of animals. The EFSA Journal. 2004;45:1-29.

8. Nakyinsige K, Sazili AQ, Zulkifli I, et al. Influence of gas stunning and halal slaughter (no stunning) on rabbits welfare indicators and meat quality. Meat Sci. 2014;98(4):701-708.
9. Verlade A, Gispert M, Diestre A, et al. Effect of electrical stunning on meat and carcass quality in lambs. Meat Science. 2003;63(1):35-38.

10. Vergara $\mathrm{H}$, Linares MB, Berruga MI, et al. Meat quality in suckling lambs: effect of pre-slaughter handling. Meat Science. 2005;69(3):473-478.

11. Linares MB, Bórnez R, Vergara H. Effect of different stunning systems on meat quality of light lamb. Meat Sci. 2007;76(4):675-681.

12. OnenC A, Kaya A. The effect of electrical stunning and percussive captive bolt stunning on meat quality of cattle processed by Turkish slaughter procedures. Meat Sci. 2004;66(4):809-815.

13. Göksoy EO, McKinstry LJ, Wilkins LJ, et al. Broiler stunning and meat quality. Poult Sci. 1999;78(12):1796-1800.

14. Farouk MM, Swan JE. Effect of rigor temperature and frozen storage on functional properties of hot-boned manufacturing beef. Meat Sci. 1998;49(2):233-247.

15. Cardiff Metropolitan University (CMU). Bradford method protocol. Practical schedule: Measurement of total protein content. Applied Food Biochemistry, CMU; 2012.

16. Honikel KO. Reference methods for the assessment of physical characteristics of meat. Meat Sci. 1998;49(4):447-457.

17. Chan JT, Omana DA, Betti M. Functional and rheological properties of proteins in frozen turkey breast meat with different ultimate $\mathrm{pH}$. Poult Sci. 2011;90(5):1112-1123.

18. Papinaho P, Fletcher D. The effects of stunning amperage and deboning time on early rigor development and breast meat quality of broilers. Poult Sci. 1996;75(5):672-676.

19. Smolinksa T, Korzeniowska M. Evaluation of the PSE and DFD abnormalities occurrence in chicken meat. XVII ${ }^{\text {th }}$ European Symposium on the Quality of Poultry Meat, Doorwerth, The Netherlands; 2005. 193 p.

20. Guàrdia MD, Estany J, Balasch S, et al. Risk assessment of DFD meat due to pre-slaughter conditions in pigs. Meat Sci. 2005;70(4):709-716.

21. Foury A, Devillers N, Sanchez MP, et al. Stress hormones carcass composition and meat quality in Large White x Duroc pigs. Meat Sci. 2005;69(4):703-707.

22. Lengerken GV, Maak S, Wicke M. Muscle metabolism and meat quality of pigs and poultry. Veterinarija ir Zootechnika. 2002;20(42):82-86.

23. Mallia JG, Barbut S, Vaillancourt JP, et al. Roaster breast meat condemned for cyanosis: A dark frim dry-like condition? Poult Sci. 2000;79(6):908912

24. Joo ST, Kauffman RG, Kim BC, et al. The relationship of sarcoplasmic and myofibrillar protein solubility to colour and water-holding capacity in porcine longissimus muscle. Meat Sci. 1999;52(3):291-297.

25. Warner RD, Kauffman RG, Greaser ML. Muscle protein changes post mortem in relation to pork quality traits. Meat Sci. 1997;45(3):339-352.

26. Vergara H, Gallego L. Effect of electrical stunning on meat quality of lamb. Meat Sci. 2000;56(4):345-349.

27. Huff-Lonergan E, Lonergan SM. Mechanisms of water-holding capacity of meat: The role of post-mortem biochemical and structural changes. Meat Sci. 2005;71(1):194-204.

28. Cheng CS. Biochemical studies of post-mortem aging, calcium ion and heating of bovine skeletal muscle. PhD Thesis, Ames, USA: Iowa State University; 1976. $250 \mathrm{p}$.

29. Hostetler RL, Landmann WA. Photomicrographic studies of dynamic changes in muscle fibre fragments. Journal of Food Science. 1968;33(5):468-470. 
30. Selmane D, Christophe V, Gholamreza D. Extraction of proteins from slaughterhouse by-products: Influence of operating conditions on functional properties. Meat Science. 2008;79(4):640-647.

31. Hui YH, Sherkat F. Handbook of Food Science, Technology and Engineering. Florida, USA: CRC Press; 2005. 3632 p.

32. French RW, Callender GR. Ballistic characteristics of wounding agents. Washington, USA: Medical Department US Army; 1962.

33. Agbeniga B, Webb EC, O’Neill HA. Influence of kosher (shecita) and conventional slaughter techniques on shear force, drip and cooking loss of beef. South African Journal of Animal Science. 2013;43(5):S98-S102.
34. Mast M, Macneil J. Effect of kosher vs conventional processing on yield quality and acceptability of broiler chickens. Journal of Food Science. 1983;48(4):1013-1015.

35. Ledward DA, Johnston DE, Knight MK. The chemistry of muscle based foods. Royal Society of Chemistry. Cambridge, UK; 1992. 330 p.

36. Greogry NG, Grandin T. Animal Welfare and Meat Production. 2nd ed. USA: Oxford University Press; 2007. 400 p. 